\title{
ESTÁ O GOVERNO DA ESCOLA SOB O COMANDO DA NORMA PADRONIZADA? \\ QUANDO A CRÍTICA MORDAZ CURTO-CIRCUITA AS \\ ORDENS DE GRANDEZA DAS FORMAS DE GOVERNAÇÃO
}

\section{IS THE SCHOOL GOVERNANCE UNDER THE COMMAND OF THE STANDARDIZED NORM? \\ WHEN SHARP CRITICISM SHORT-CIRCUITS THE ORDERS OF WORTH OF THE FORMS OF GOVERNMENT}

\author{
José Manuel Resende \\ Centro Interdisciplinar de Ciências Sociais, Universidade de Évora. Largo dos Colegiais, 2, 7000-812 Évora, \\ Portugal. Email: josemenator@gmail.com \\ Luís Gouveia \\ Centro Interdisciplinar de Ciências Sociais, Faculdade de Ciências Sociais e Humanas, Universidade NOVA de \\ Lisboa. Av. de Berna, 26C, 1069-061 Lisboa, Portugal.Email: lcgouveia86@gmail.com
}

\section{David Beirante}

Centro Interdisciplinar de Ciências Sociais, Faculdade de Ciências Sociais e Humanas, Universidade NOVA de Lisboa. Av. de Berna, 26C, 1069-061 Lisboa, Portugal. Email: davidbeirante@gmail.com

\begin{abstract}
Resumo: O conjunto de mudanças que ocorrem nos sistemas educativos nas últimas décadas tem como vetor fundamental a mudança do programa de justiça que orienta o seu funcionamento. É o paradigma de escola eficaz que ganha paulatinamente terreno. Esta evolução no plano dos princípios de justiça e lógicas de funcionamento tem repercussões nas formas de exercício da atividade docente, enquanto pilar incontornável para a prossecução destas novas orientações. Ora, estas novas demandas não significam que elas sejam mecanicamente assimiladas por estes profissionais. É perscrutável uma diversidade de lógicas atuantes, assentes em diferentes composições de regimes de envolvimento na ação, no exercício da atividade, e que entram em tensão de diferentes formas com as lógicas performativas incrustadas no funcionamento do sistema educativo. Alguns dos dados recolhidos no âmbito de um projeto de investigação fornecem o suporte empírico para as indagações que se pretendem desenvolver sob um enfoque teórico de cariz pragmatista.
\end{abstract}

Palavras-chave: programa de justiça escolar, escola performativa, regimes de ação, professores do Ensino Básico e Secundário.

\begin{abstract}
The set of changes that has taken place in the educational systems in the last decades has had, as a fundamental vector, changes in the justice program that regulates its functioning. It is the paradigm of effective school that has gradually gained influence. This evolution of the principles of justice and logics of operation has repercussions on the forms of exercise of the teaching activity as an essential pillar for the attainment of these new orientations. However, these new demands do not mean that they are mechanically assimilated by these professionals. Namely, it is possible to discern a diversity of acting logics, based on different compositions of regimes of action, in the exercise of the professional activity, that comes into tension with the performative logics embedded in the functioning of the educational system. Data collected during the course of a research project pempirically supports the inquiries carried out under a pragmatist theoretical approach.
\end{abstract}


Keywords: school justice program, performative school, regimes of action, Basic and Secondary teachers.

\section{Entre a ontogénese e a tecno-génese: Os efeitos da estandardização dos dispositivos de governação escolar nos mandatos dos professores}

Como governar a escolarização pública está hoje na ordem do dia nas reflexões sociológicas. Destacar o hoje não significa ressaltar uma temporalidade ainda curta naquilo que toca a este objeto. Há muito tempo que sociólogas e sociólogos portugueses tomam a questão da administração e gestão escolar como objeto de pesquisa (Afonso, 1997, 1998; Barroso e Carvalho, 2008; Barroso, Carvalho, Fontoura e Afonso, 2007; Lima, 2011, 2012, 2013; Lima, Estêvão, Silva, Torres e Sá, 2006).

A novidade aparece ligada ao conceito de governamentalidade trazida para a Sociologia por inspiração dos trabalhos produzidos por Michel Foucault. Na verdade, Foucault trabalha o governo das populações e das instituições através da entrada da racionalidade como dispositivo central da modernidade política. Ora, a escolarização pública, trabalhada pela forma escolar moderna, traz outras práticas que se ligam aos saberes ali transmitidos e que exigem dos corpos a adoção de ações adequadas à racionalidade que a socialização política imprime, quer aos alunos, quer aos professores. Neste sentido, para Foucault, "esta nova racionalidade política apoia-se sobre aparelhos específicos de governo e sobre um sistema de saberes. Estes dois elementos, uma vez agenciados, apresentam-se como o fundamento de dispositivos que constituem os operadores materiais do poder" (Rui, 2013, p. 68).

Insistir na governação da escolarização significa, na nossa reflexão, que os seus efeitos incidem sobre as práticas de quem exerce, nas escolas, o mandato destinado à transmissão dos conhecimentos para determinados destinatários, os alunos, e segundo a conformidade com a sua idade escolar. Mas exerce também outros efeitos nas maneiras de agir dos recetores das mensagens pedagógicas.

Então, o que nos afasta da conceção de Foucault, apesar de usarmos o seu conceito de governamentalidade (Foucault, 1991)? Tal como menciona Sandrine Rui (2013), o entendimento adotado do conceito de governamentalidade, e por extensão do conceito de governação, tem sido justamente produzido com a ausência nas suas reflexões das operações críticas dos atores quando são confrontados com uma dada ordenação das grandezas injustas e da sua economia decorrentes dos projetos e dos dispositivos de governação adjudicados às instituições modernas, aqui focalizada no interior dos estabelecimentos de ensino. 
A inacessibilidade em apreender a crítica social produzida sobre os dispositivos e os projetos de que se alimentam e em que se baseiam reduzem em muito as ilações sociológicas que se retiram dos efeitos dos modelos de governação e da sua aplicação nos contextos de trabalho escolares. Ora, é isto que temos estado a evitar fazer, uma vez que a governamentalidade dos territórios escolares nem sempre aciona dispositivos suficientemente extensos que interfiram, por exemplo, nos espaços intercalares (Breviglieri, 2007) que são conexos aos espaços da escola. Por outro lado, os princípios normativos que orientam os modelos aplicados como dispositivos da governação não deixam de ser objeto de críticas e de denúncias, como temos vindo a mostrar em diferentes textos, quer apresentados por docentes, quer referenciados pelos alunos (Resende, Beirante e Gouveia, 2019).

Neste sentido, tem sido nosso propósito deslocar a problemática da governação dos órgãos que administram as escolas para as modalidades de direção assumidas pelos regimes de envolvimento na ação que os docentes manifestam quando se confrontam com as orientações normativas a estes dirigidas, quer pelas direções das escolas, quer pelos seus conselhos pedagógicos. Não se menoriza o trabalho hermenêutico desenvolvido por docentes que têm a seu cargo o exercício de comando das atividades escolares, incluindo nelas as atividades letivas e pedagógicas. Contudo, as nossas indagações têm sido outras. Temos dado conta de que as orientações normativas de governação da escolarização transmitidas pelos órgãos de gestão das escolas têm sido experimentadas por docentes, com diferentes temporalidades no seu posto, como momentos críticos conducentes a uma problematização sobre o seu mandato profissional, justamente em virtude das consequências que a padronização normativa da governação tem imprimido nas suas práticas pedagógicas a partir, sobretudo, dos finais da primeira década do século XXI.

Dito de outra maneira, os princípios políticos e morais inscritos nas cartografias culturais em que se baseia a jurisdição produzida sobre este assunto (Abbott, 1988) têm de ser sociologicamente trabalhados no âmbito das operações críticas fornecidas pelos docentes quando estes são confrontados com as consequências daquelas orientações nas suas práticas profissionais. Isto significa que os novos investimentos em formas (Thévenot, 1986) que ensaiam a constituição de práticas pedagógicas ritualizadas e comuns entre os professores, com o propósito de estes cumprirem a grandeza máxima ali consubstanciada - a referida eficácia nos resultados finais das aprendizagens e menos a eficácia dos processos relacionados com a efetiva aquisição e monitorização dos conhecimentos captados pelas modalidades de transmissão -, não se extraviem no emaranhado das experiências profissionais com que os professores se defrontam no seu local de trabalho. Bem pelo contrário: os efeitos que as novas categorias intentam classificar e qualificar as 
práticas dos professores em ação são recursivamente por estes apropriados para tecerem operações críticas mordazes, mostrando-se indisponíveis para os aceitar como válidos e credíveis, quer para o exercício das práticas pedagógicas que realizam na sua lecionação, quer para o exercício da socialização política que lhes incube fazer junto dos seres mais novos - os seus alunos.

É por isso que, no desdobramento dos processos de governamentalidade a que as instituições são submetidas, com destaque para a escola, a aplicação dos princípios que animam os seus processos de governação, e que nutrem os seus dispositivos, não deixa de estar sujeitos a um trabalho interpretativo crítico da parte dos atores que ali fazem o seu trabalho. Sem ter em consideração, na análise sociológica, a exercitação destas lidas da parte dos profissionais, gera-se uma real incompletude na compreensão daquilo que se passa nos estabelecimentos de ensino, designadamente aquilo que acontece nas artes em fazer o comum no plural nos seus locais de trabalho (Resende e Gouveia, 2013).

Na verdade, os profissionais de ensino não deixam por mãos alheias o trabalho de confeção das suas biografias como professores. E as suas biografias apresentam-se a estes também como espelhos ontológicos. Por outras palavras, o cuidado de si (Foucault, 1998, 2010) é crucial para cuidarem dos seus alunos. E cuidar destes requer que as suas práticas pedagógicas se vinculem a projetos globais de intervenção no âmbito daquilo que temos vindo a designar como os exercícios de socialização política de que os adultos na escola se mostram merecedores de exercerem em pleno.

Porém, as modalidades de governação em curso, e em particular a sobreposição do princípio da regulação numérica que deve nortear a prestação de contas do seu trabalho na escola, são, para muitos dos professores, inaceitáveis, designadamente em virtude das suas consequências na formação integral dos seus discípulos. Do seu trabalho na escola e dos exercícios que este exige para o desenvolvimento desta particular socialização emanam desafios que os levam a espicaçar corrosivamente a padronização normativa que as orientações da governação pretendem impor - e a trazer destas experiências a opressão em resultado das consequências limitativas que observam ao aplicar aquelas diretrizes.

Os docentes não menorizam os equipamentos técnicos que regulam o seu trabalho. Não desprezam a importância dos sumários, dos relatórios, da contabilização dos resultados escolares, da fabricação das múltiplas taxas estatísticas com as qualificações que estas produzem sobre os classificados. Não desqualificam os processos de avaliação, classificação e categorização do seu trabalho a que se têm de sujeitar no âmbito desta política de prestação de contas. Insurgem-se contra o excesso e a unicidade da medida, como vamos observar na tessitura dos seus 
comentários críticos em face dos enquadramentos limitados que a governação intenta trazer às suas práticas profissionais (Resende, 2017). O que reclamam através destas vozes é que os seus modos de existir como profissionais não os podem levar a circunscrever as suas maneiras de fazer a escolarização à volta de uma tecno ontologia, exclusivista e baseada em procedimentos unilaterais e unidimensionais. Falar de si como profissionais através da substancialização do significado atribuível ao número é um absurdo pela natureza estremada como podem interpretar o seu ser, quer como ser vivo, quer como ser humano - os dois compostos nas diversas maneiras de se engajarem em múltiplos regimes de envolvimento da ação.

O seu mandato é bem mais amplo que aquele que é pressuposto nas aspirações tecidas à política da ditadura do número (Resende, 2010). Requer a preparação das novas gerações para o confronto com o mundo que os vai rodeando à medida que o seu corpo opera em si, através dos outros, o amadurecimento expectável. Mas, para a maturação do corpo da criança, do adolescente e do jovem que têm pela frente, o número não é em si mesmo uma substância. O resultado consubstancia um processo sinuoso e complexo de múltiplas aprendizagens que não se podem reduzir exclusivamente à aprovação nos exames finais.

\section{Considerações metodológicas prévias}

Antes de proceder à apresentação da análise empírica, importa ainda fazer um breve enquadramento metodológico. O presente artigo parte de um conjunto de dados recolhidos a partir de um projeto de investigação ${ }^{1}$. Tendo como pano de fundo a contestação pública levada a cabo pelos professores do Ensino Básico e Secundário a uma reforma educativa que ocorre em Portugal (nomeadamente, a reforma do Estatuto da Carreira Docente de 2007), constituindo este um momento de particular intensidade crítica em torno das conceções sobre o mandato profissional, a pesquisa centra-se na problemática da pluralidade de juízos em torno da profissão docente (Gouveia, 2017). Uma das dimensões de análise prende-se, justamente, com as conceções em torno do mandato profissional no quadro da emergência do paradigma de eficácia escolar e constituição de um sistema de governação por normas padronizadas à escala transnacional (Thévenot, 2007) - e que, consequentemente, trazem implicações ao nível das práticas pedagógicas dos professores, nas suas formas de coordenação da ação e envolvimento na atividade enquanto principais agentes do trabalho de socialização realizado na instituição escolar.

A partir desta problemática, o trabalho de campo incide sobre cinco estabelecimentos de ensino do sistema público Português. A escolha dos mesmos obedece ao pressuposto metodológico fundamental de selecionar estabelecimentos de 
ensino geograficamente dispersos e com públicos escolares contrastantes do ponto de vista da sua composição social. Três escolas da amostra situam-se no Distrito de Lisboa (duas na cidade capital e outra num município contíguo); uma situa-se a Norte, no distrito de Aveiro; e uma última situada no Interior, na região do Alto Alentejo.

O trabalho de campo desenvolvido assenta fundamentalmente em duas técnicas de recolha e análise de dados: entrevistas semidiretivas (ao todo, 40 entrevistas realizadas a docentes do Ensino Básico e Secundário; oito em cada escola que compõe a amostra) e um questionário por cenários (foram validados 112 no conjunto das 5 escolas). Em cada estabelecimento de ensino, e mediante uma amostragem não probabilística por quotas, os inquiridos são selecionados tendo em vista um conjunto de variáveis de caracterização: vínculo institucional (contratado e do quadro), área disciplinar de ensino e anos de atividade profissional.

No caso específico do questionário aplicado, o cenário constitui uma narrativa dilemática a partir da qual os inquiridos são convidados a expor os juízos críticos em torno do enredo em questão, dando conta das suas competências para agir mediante diferentes regimes de ação (Danic, Delalande e Rayou, 2006). Os cenários são construídos a partir de situações experienciadas e apresentadas recorrentemente pelos inquiridos como injustas em entrevistas exploratórias realizadas (sendo estas narrações agrupadas posteriormente em polos pelo investigador). No âmbito desta pesquisa, o questionário aplicado é composto por 8 cenários, construídos em torno de 4 eixos de análise que orientam a investigação: a) avaliação e progressão, b) colegialidade e coordenação, c) autoridade docente e d) mandato profissional. Em função daquilo que é o objeto do presente artigo, é escolhido um dos cenários que integra o último eixo, e que versa diretamente as conceções construídas pelos docentes em torno daquilo que é o seu mandato profissional ${ }^{2}$.

Ora, o percurso analítico empreendido nesta pesquisa é orientado pelo programa teórico comummente designado por Sociologia Pragmática - em particular, a sociologia dos envolvimentos, desenvolvida por Luc Boltanski e Laurent Thévenot. Este quadro teórico propõe uma conceção específica de ação (Thévenot, 2006). Nomeadamente, ela é entendida a partir das modalidades pelas quais os indivíduos se envolvem na ação e dos formatos de coordenação com os outros e consigo próprios. Estas diferentes modalidades de envolvimento designam-se por regimes de envolvimento na ação. Cada regime é convocado pelos indivíduos em situação - em função, justamente, do juízo realizado sobre essa mesma situação. Tal juízo ou trabalho interpretativo realizado implica a seleção e organização de elementos da situação por parte do indivíduo, desenvolvendo a ação que convém (Thévenot, 1990) - no sentido em que ela resulta de uma avaliação, de um juízo situado. 
São, nomeadamente, distinguidos três regimes de ação: o regime de ação em plano, regime de justificação pública e regime de ação familiar. No caso do regime em plano, a ação é orientada de forma estratégica e em que o formato de envolvimento é funcional por referência a determinados propósitos. Sendo este regime de ação orientado para atingir objetivos estabelecidos e decorrendo num ambiente funcionalmente preparado, a sua projeção favorece a produção de regras e normas padronizadas. Estes resultam de um trabalho intenso de investimento de forma (Thévenot, 1986) para a elaboração de acordos em torno de benchmarks, procedimentos e testes - objetos e dispositivos que definem a norma estandardizada (Thévenot, 2007, 2009). Esta operação pode envolver o compromisso entre diferentes ordens de grandeza, apesar de se apoiar em seres oriundos do mundo industrial. Assim, no caso do envolvimento em plano, sendo o bem visado a satisfação gerada por uma ação realizada, a ação do professor é orientada por um conjunto de indicadores de desempenho - na forma de normas padronizadas - que orientam a sua conduta. É, pois, mediante esses indicadores que se envolve na sua atividade enquanto medida da qualidade do trabalho desenvolvido - indicadores que se sobrepõem a formas de envolvimento a partir do regime de justificação pública, caracterizado por convenções de maior abrangência e visando noções do bem comum.

No regime de justificação pública, a ação é orientada em referência a ordens de grandeza, enquanto convenções de grande alcance cognitivo e moral socialmente difundidas e que visam qualificar os seres e ações envolvidos numa situação determinada e em função de uma determina conceção do bem comum. Releva-se em particular neste artigo aquelas que são quatro ordens de grandeza nas quais estão alicerçadas (em composições distintas) as conceções produzidas pelos docentes sobre o seu mandato profissional e o trabalho qualificador dos alunos (Resende, 2003, 2010): grandeza industrial (enfoque na eficácia do trabalho de instrução enquanto transmissão dos conteúdos programáticos da respetiva área disciplinar, sendo essa eficácia medida por dispositivos de mensuração/quantificação); grandeza cívica (enfoque na consciencialização dos alunos enquanto cidadãos e a sua mobilização em torno de causas comuns); grandeza doméstica (enfoque na competência de educar os discentes enquanto inculcação de valores e regras de comportamento); e grandeza inspirada (enfoque na exploração criativa do conhecimento, entrando particularmente em tensão com o mundo industrial e um trabalho qualificador orientado por ferramentas que conferem uma rotina industrial à prática pedagógica).

No regime de ação familiar, a ação decorre num registo de proximidade, localizada, em que o indivíduo age a partir de uma familiarização dinâmica com as pessoas e objetos envolvidos, por intermédio de uma acomodação mútua do indivíduo ao seu ambiente direto (Thévenot, 2006). A título de exemplo, enquadra-se 
num envolvimento familiar o investimento afetivo na relação com a figura do discente, num registo relacional íntimo que implica a suspensão de formatos de envolvimento a partir de critérios de validade geral, associados ao regime de justificação pública.

É justamente a partir deste quadro teórico que se pretende analisar os regimes de ação a partir dos quais os professores constroem as operações críticas em torno do seu mandato profissional, articulando esses entendimentos com aquilo que são as mudanças que ocorrem nas últimas décadas no programa de justiça escolar (Derouet e Derouet-Besson, 2009) e as consequências da padronização normativa da governação escolar nas suas práticas pedagógicas - num acompanhamento do trabalho crítico desenvolvido pelos docentes convocando diferentes composições entre regimes pragmáticos.

\section{A emergência do paradigma da eficácia e as repercussões no funcionamento da instituição escolar em questão}

Um olhar sobre a evolução em torno das políticas educativas ao longo das últimas décadas permite dar conta das configurações distintas do ponto de vista da composição entre construções políticas, instrumentos estatísticos e teorias de natureza económica, social e política que estão na base dessa mesma evolução (Normand, 2001; Thévenot, 2011). A análise a partir de uma sociologia dos envolvimentos (Boltanski e Thévenot, 2006; Thévenot, 2006) permite-nos dar conta das diferentes gramáticas em que estas configurações assentam.

Um elemento incontornável das políticas educativas da segunda metade do século XX é a massificação da escolarização. O período do pós-Segunda Guerra Mundial é marcado pela emergência de perspetivas políticas orientadas para a redução das desigualdades sociais, com enfoque no impacto que a origem social dos indivíduos pode ter do ponto de vista do desempenho escolar e académico - e as respetivas repercussões do ponto de vista das perspetivas de carreira e trajetória no mercado de trabalho. A solidariedade cívica (Boltanski e Thévenot, 2006) é a base justificativa central das políticas em prol de uma escolarização prolongada e massificada, entendida como um fator determinante para alcançar o desiderato de promover uma maior mobilidade social e igualdade de oportunidades. No caso português, só no fim da primeira metade dos anos sessenta é que a entrada de um maior número de alunos se começa a fazer sentir nas escolas do Ensino Técnico e do Ensino Liceal (Resende, 2003).

É já sobretudo nos anos 80 que se assiste à emergência de uma nova configuração assente numa composição distinta, entre as ordens de grandeza industrial e 
mercantil. Por um lado, o enfoque crítico é colocado na questão da eficiência do funcionamento dos sistemas educativos, no sentido de uma maior associação entre a formação no espaço escolar e as competências necessárias e com retorno no sistema produtivo - com o privilégio de competências-base nas estruturas curriculares (Normand, 2005) - , além da aferição da eficiência no funcionamento dos sistemas educativos na ótica da relação entre o investimento (alocação de recursos) realizado e os resultados escolares obtidos. Neste último caso, a estatística enquanto elemento de prova assume um papel determinante nestas operações críticas, com a sofisticação de modelos econométricos produzidos em gabinetes de estatística a demonstrarem resultados distintos do ponto de vista dos resultados escolares entre estabelecimentos de ensino com perfis estudantis semelhantes (Dionísio, 2010). As teorias económicas do capital humano - numa perspetiva de relação estreita entre a escolarização (e aquisição de conhecimentos e saber-fazer) e o desenvolvimento económico no contexto de uma economia do conhecimento - constituem um suporte teórico fundamental desta perspetiva em torno da política educativa (Thévenot, 2011).

Por outro lado, ao invés de uma planificação central por cada Estado e respetivo órgão governativo do ponto de vista das políticas governativas, o locus da governação é progressivamente deslocado dos estados nacionais para instituições transnacionais, encarregues de produzir corpos de estatística (como é o caso da OCDE) (Normand, 2005). Sem uma intervenção direta do ponto de vista das políticas educativas delineadas, os corpos de estandardização produzidos servem, no entanto, de referenciais para a ação política num contexto de competição entre os diferentes países. Esta composição de ordens de grandeza constitui a base da lógica gestionária no funcionamento do Estado e na prestação dos serviços públicos (Ogien, 2013) e da constituição de um sistema de governação por normas padronizadas internacional a uma escala sem precedentes (Thévenot, 2009, 2011), e com particular destaque para o espaço da União Europeia (Thévenot, 2007).

Convém também frisar que os princípios justificativos da grandeza mercantil começam a preocupar os docentes que entram na carreira nos anos 90 . No dealbar do século XXI, dão nota dessa preocupação (Resende, 2010) ao referir-se à competição entre escolas do Ensino Secundário naquilo que diz respeito às manifestações dos pais em matricular os filhos em estabelecimentos que ofereçam garantias de qualidade do ensino e aprendizagem, que permitam à sua descendência ter notas elevadas nos exames finais e entrar nos cursos universitários públicos que conferem maiores garantias de emprego com segurança - como é o caso dos cursos de medicina, de arquitetura e, mais tarde, de algumas áreas das engenharias (com a significativa perda da arquitetura em função dos efeitos da crise financeira iniciada em 2009). 
Porém, a constituição de um mercado escolar assente na exteriorização de ações dos pais baseados em interesses de ganhos imediatos e a longo prazo para os seus filhos, através da natureza dos diplomas a conquistar com a entrada na universidade, vai ter influências nos projetos pedagógicos que as escolas tendem a oferecer a quem as procura como contexto de trabalho escolar. E é assim que estes notam a diversidade de projetos pedagógicos oferecidos por escolas geograficamente perto umas das outras, sobretudo na área metropolitana de Lisboa.

E ainda de acordo com os nossos informantes, as interferências externas mercantis que incidem na composição das morfologias escolares transportam para dentro das escolas discussões em torno das orientações normativas a conferir à escolarização pública. Para que serve a escolarização pública? Em que princípios orientadores devem assentar as funções e finalidades das políticas e as ações públicas escolares de modo a que escolarização concretize as suas aspirações baseadas em uma aprendizagem de qualidade para todos? Ora, as respostas a estas interrogações têm à partida de estar expostas nos projetos educativos e em outras convenções cujos protocolos têm de ter a anuência dos seus órgãos de gestão.

Contudo, neste contexto de uma instituição escolar sob o domínio da eficácia e do interesse enquanto programa de justiça (Derouet e Derouet-Besson, 2009), são as diversas ramificações do ponto de vista do funcionamento de todo o edifício do sistema educativo que surgem como particular objeto de crítica por parte dos professores quando se pronunciam sobre a realidade profissional (Resende, 2010). Entre várias dimensões que são objeto de apreciação, identifica-se nos discursos dos professores o problema relativo a constrangimentos que os Exames Nacionais e outros dispositivos (provas de aferição) de medição da eficácia do trabalho docente do ponto de vista das aprendizagens dos alunos exercem no quotidiano, e com impacto na relação pedagógica com os alunos. É o que sobressai do discurso desta docente de Filosofia.

Portanto o 'professor eficaz' é aquele professor que passa o ano a preparar os alunos para os exames, com tudo o que isso significa e implica. Isso implica que o professor não tem outras preocupações em termos de formação, em termos de ética, em termos de formação estética dos alunos porque o professor está simplesmente a funcionar como uma sebenta para os alunos decorarem aquilo que vai ser importante para os exames. E, portanto, esse é um modelo extremamente redutor, agressivamente redutor. Faz da escola uma espécie de fábrica. [...] Tento que não constranja excessivamente, tentando levar sempre em consideração que há coisas que são importantes para os alunos mesmo que depois não sejam matéria de avaliação, matéria de exame. Mas acaba sempre por constranger. Tento que não constranja excessivamente, mas o que eu quero dizer é que se eu fizer a comparação entre a maneira como eu trabalho com os alunos hoje e há 15 anos, eu vejo perfeitamente a diferença daquilo que eu era capaz de fazer e propor-lhes, e que neste momento não posso propor-lhes porque não tenho tempo, não tenho condições e 
tenho a preocupação da eficácia. [...] Em termos culturais, estou a ser um pior professor; em termos de eficácia estou a ser um bom professor. (Entrevista; E20; professor de Filosofia; 28 anos de atividade; docente do Quadro)

É o "'professor eficaz', enquanto paradigma no exercício da atividade docente promovido na atual forma de governação escolar (Normand, 2005) consubstanciado no fim último de "preparar os alunos para os exames", que está também no centro do discurso do entrevistado. Mas o reconhecimento da centralidade da eficácia é operado pelo docente de um ponto de vista crítico. Sujeita-se em parte a estas orientações para não prejudicar a performance dos seus alunos nos exames. No entanto, revela nas operações críticas os efeitos redutores destas orientações políticas, não dando tempo pedagógico para falar com os seus alunos de assuntos que confiram a possibilidade de a figura grande se encontrar baseada nas incitações de base cultural.

É verdade que são as preocupações do ponto de vista da formação e educação (entre as quais introduz as questões de natureza ética, moral e estética) que no seu entender acabam amputadas num quadro de um paradigma que entende como "agressivamente redutor" daquilo que devem ser as funções da instituição escolar e, consequentemente, suas enquanto docente. Na exposição que faz, sem se dar completamente (con)vencido da bondade destas orientações, este paradigma de ensino traduz-se, na prática no que desqualifica como sendo um ensino promotor de automatismos (ao invés do pensamento crítico), no privilégio de conhecimentos com base em sebentas, através das quais os alunos decoram os conteúdos e em função do exame enquanto instrumento padronizado de aferição.

Na ilustração dos efeitos nocivos concretos, o docente reporta-se igualmente à condução dos momentos de aula tendo o exame e os respetivos conteúdos como referenciais e segundo um conjunto de dispositivos padronizadores da atividade (programa curricular, objetivos e metas curriculares, descritores de desempenho, competências a adquirir pelos alunos, etc.). Sem questionar a importância ou necessidade de existência destes dispositivos industriais de coordenação da ação (Thévenot, 2014), além de conferirem pouca latitude ao professor, outros conteúdos e temáticas acabam descurados - sendo este duplo condicionamento que se afigura como um elemento constrangedor do cumprimento do mandato enquanto docente como o concebe. $\mathrm{O}$ "tempo" de aula afigura-se excessivamente formatado por este conjunto de dispositivos. Na sua comparação com os primeiros anos de carreira, na forma como a relação pedagógica surge estruturada, descreve uma evolução da profissão em que a latitude para a exploração inspirada de outros itinerários e conhecimentos de que anteriormente gozava mingua paulatinamente um constrangimento decorrente da crescente influência que a gramática industrial assume no funcionamento do edifício escolar enquanto instituição. 
Dando nota crítica destas sujeições, estas são em parte colmatadas por autorrealizações suas com a introdução de outros assuntos de base inspirada de modo a que a escola fábrica não produza todos os seus efeitos redutores em termos de aprendizagens. Reconhece que cede, por comparação com a atividade pedagógica de outrora, mas não em tudo. Há frestas nas sinuosidades das práticas e comunicações pedagógicas que lhe dão a possibilidade de introduzir outras questões para si maiores e que para o programa são menores.

A crítica ao mundo industrial, transversal ao excerto e aos diversos pontos que constituem o ponto de vista do docente, adquire a sua expressão mais clara com a metáfora da fábrica para fundamentar a sua visão crítica ao que perceciona como sendo o atual modo de governação da instituição escolar. Neste contexto político, do ponto de vista do reconhecimento organizacional, a grandeza do professor reside eminentemente na "eficácia" de que dá prova, sendo os resultados obtidos no exame (ou noutras provas de aferição de conhecimentos e competências adquiridas) o elemento privilegiado nessa aferição. Neste arranjo composicional, ficam numa posição subalterna os restantes mundos escolares que integra no seu mandato enquanto docente (Resende, 2010).

Outro professor, de Educação Física, reflete igualmente sobre o impacto do corrente paradigma a partir da sua conceção em torno do que são as funções da instituição escolar, e com particular enfoque na questão da estrutura curricular:

Eu acho que hoje a escola está a dar pouca importância à capacidade de reflexão e crítica dos alunos e está a dar-se demasiada importância ao conhecimento lógico "Isto é assim porque é assim". As coisas são pouco questionadas e pouco refletidas. E penso que é a capacidade de um aluno de desenvolver projetos na escola onde os alunos tenham uma intervenção mais crítica e mais de reflexão sobre as coisas, neste momento existe muito pouco. E eu acho que isto vai condicionar eles no futuro, a pensar por eles próprios sobre as coisas. Essa é uma das coisas que eu noto nestes últimos anos. Um pouco a questão da massificação dos exames, da carga horária excessiva para os alunos... Portanto, eu acho que a escola centrou-se muito nas questões do Português e da Matemática e apenas na aprendizagem em si, e não está a criar os espaços onde os alunos possam mostrar e desenvolver outras habilidades que tenham: os clubes, o desporto escolar, as atividades de teatro, música... Outro tipo de atividades que também desenvolvem a formação individual de um jovem. (Entrevista; E15; género masculino; professor de Educação Física; 15 anos; docente do Quadro)

É a "massificação dos exames" que surge aqui no cerne do diagnóstico. Num plano mais profundo do seu trabalho qualificador (Resende, 2010), é a "capacidade de reflexão e crítica" que é secundarizada, em benefício do que caracteriza como "conhecimento lógico", enquanto interiorização de conteúdos ("são pouco 
questionadas e pouco refletias"). O exame, como referencial da atividade pedagógica, contribui para um ensino reprodutor - e o objetivo mensurável sobrepõe-se ao fim originalmente visado (Thévenot, 2011).

Um indicador palpável apontado pelo entrevistado prende-se com o relevo que disciplinas consideradas nucleares - como é o caso do Português e da Matemática - adquirem no conjunto da oferta curricular ${ }^{3}$. Outras vertentes enriquecedoras do projeto educativo do estabelecimento de ensino (como "clubes", "desporto escolar", "atividades de teatro", "música") que contribuem para a "formação individual" acabam por ser preteridas ou relegadas para um plano excessivamente subalterno. O trabalho acaba neste sentido empobrecido face ao que entende ser uma sobreposição do mundo industrial a outros mundos no trabalho de socialização realizado no seio da instituição escolar.

Transversal a este conjunto de excertos surge, pois, a questão do arranjo compósito entre diferentes ordens de grandeza que deve estar subjacente, num primeiro plano, à construção do currículo escolar e, em última análise, ao mandato da instituição escolar e ao seu mandato dos docentes enquanto principais agentes do trabalho de socialização política nela realizado (Resende, 2010).

É com o intuito justamente de explorar esta questão que, no âmbito do questionário por cenários aplicado a professores do Ensino Básico e Secundário, uma das narrativas procura explorar as diferentes perspetivas construídas pelos docentes em torno da composição entre diferentes ordens de grandeza em que deve assentar o currículo escolar e consequentes juízos do ponto de vista das conceções em torno do mandato escolar e profissional.

A narrativa (figura 1) centra-se num momento particular do quotidiano destes profissionais de ensino: uma reunião do Conselho Pedagógico. Este órgão tipificado, de acordo com a orgânica centralmente definida pelo Ministério da Educação, é responsável pela coordenação e supervisão pedagógica e orientação educativa da respetiva escola ou agrupamento de escolas. Concretamente, um dos pontos da reunião que se encontra a decorrer prende-se com a execução de um projeto de formação dos discentes no âmbito do programa para a saúde Afetos e Educação para a Sexualidade. Integrada pelo Ministério da Educação na oferta curricular das escolas com carácter obrigatório, o seu conjunto de objetivos envolve, sumariamente, "contribuir para a melhoria dos relacionamentos afetivo-sexuais entre os jovens" e "redução de possíveis ocorrências negativas decorrentes dos comportamentos sexuais, como a gravidez precoce e infeções sexualmente transmissíveis" (DGE, 2019). No seu conteúdo educativo, identifica-se um arranjo composicional entre os mundos cívico e doméstico, visando questões de saúde pública, mas também quadros orientadores de comportamentos no contexto da vida afetiva dos jovens. 
Regressando ao caso concreto do cenário apresentado, a reunião do Conselho Pedagógico debruça-se sobre a constituição de um grupo de docentes disponível para a delineação e execução de um projeto de educação sobre a referida temática. Contudo, uma das docentes, de Biologia, apronta-se a manifestar a sua indisponibilidade. Na justificação que elabora, o regime industrial sobressai: a preparação dos alunos para os Exames Nacionais, enquanto momento de mensuração das aprendizagens retidas pelos alunos, sobrepõe-se relativamente àquele projeto integrado da vertente formativa e educativa do currículo escolar.

A escolha da disciplina, Biologia, não é inocente. Integrando o agrupamento de disciplinas relativas às Ciências (Experimentais), logo, elencada entre as competências-base (Normand, 2005), é uma área tida como prioritária no quadro de uma instituição escolar sob o paradigma da eficácia industrial. Ela contrasta, pois, com o estado de pequena grandeza que um programa de educação como o relativo à Educação Sexual assume nas perspetivas engrandecedoras do mundo industrial relativamente ao mandato escolar, em detrimento de outros mundos (como o cívico e doméstico).

O objetivo deste cenário é, então, o de analisar como se posicionam os inquiridos perante esta narrativa, que os remete para as diferentes reflexões em torno das funções da Escola e, por decorrência, as suas funções enquanto profissionais de ensino. Nestes juízos, são suscetíveis de serem convocados arranjos composicionais entre diferentes ordens de grandeza em jogo, nas quais suportam as operações de crítica e justificação e regimes de envolvimento na ação (Boltanski e Thévenot, 2006; Thévenot, 2006).

Numa reunião do conselho pedagógico, discute-se a possibilidade de algum dos professores se oferecer para trabalhar num projeto de formação com os alunos sobre educação sexual, considerando a importância desta matéria para a saúde dos jovens. Perante a tentativa de constituir um grupo de professores disponíveis, um dos docentes presentes, uma professora de Biologia, responde prontamente: "Desculpem, mas não tenho tempo para pensar nessas coisas. Eu tenho é de pensar nos exames nacionais".

Das soluções expostas em baixo, indique a mais injusta e a mais justa.

A. A educação sexual não deve fazer parte das finalidades da escola.

B. A educação sexual deve ser tratada apenas em disciplinas específicas para o efeito.

C. Os conteúdos cognitivos e a melhoria dos resultados escolares dos alunos devem ser a prioridade dos estabelecimentos de ensino.

D. A cada professor deve ser dada autonomia para abordar as questões de educação sexual nas suas aulas se assim o entender.

E. Questões como a educação sexual devem ocupar um lugar importante nos conteúdos curriculares dos estabelecimentos de ensino.

Figura 1 Cenário do questionário aplicado 
Não sendo possível incidir a análise sobre aquelas que são as categorias mais representativas dado os constrangimentos de espaço, destaca-se no presente artigo a categoria que assume clara hegemonia relativamente às restantes ${ }^{4}$. A educação sexual é uma importante finalidade da escola/deve ser prioritária (48,6\%).

Procurando dar conta da diversidade interna de perspetivas que se enquadra nesta categoria, um primeiro grupo de inquiridos caracteriza-se por operações de justificação em que o mundo cívico assume uma importante base nas perspetivas aventadas.

A escola atual multiplicou a suas finalidades, jamais se cingindo ao ministério do conhecimento, tal como era a do passado. Perante a desestruturação crescente da família e dos seus valores e a propagação multimédia de informação errada, desajustada e incoerente, a escola será ainda o último reduto de uma educação integral possível para muitas crianças e jovens. (Questionário; A10; género masculino; professor de Filosofia; 28 anos de atividade; docente do Quadro)

Para a sociedade não deve interessar só os conteúdos cognitivos, mas também outros saberes.

Verifica-se que atualmente a família está a delegar na Escola a socialização. É necessário a aprendizagem de novos valores.

A escola tem de formar, educar jovens, pessoas, cidadãos em paralelo com os conteúdos pré-estabelecidos para criar cidadãos mais esclarecidos. (Questionário; B18; género feminino; professor de Economia e Contabilidade; 29 anos de atividade; docente do Quadro)

A ordem de grandeza cívica surge patente no discurso da primeira inquirida no relevo que coloca na responsabilidade social da escola: no quadro daquilo que caracteriza como um contexto social marcado pela "desestruturação crescente da família e dos seus valores", além da multiplicidade de canais de informação no contexto das novas tecnologias potenciadores de equívocos, é assacada à escola a responsabilidade de se afirmar como um esteio, o "último reduto" de uma "educação integral" do aluno na sua dimensão enquanto criança e enquanto jovem (onde, portanto, o mundo doméstico não deixa de estar incluído nas funções da instituição escolar). Esta responsabilidade social que é evocada contrasta, de resto, com uma conceção da escola enquanto "ministério do conhecimento" alicerçada nos mundos industrial e inspirado, e que a entrevistada situa temporalmente como estando associada a um momento temporal "passado" - e que se afigura como incompatível com as referidas mudanças sociais, às quais a Escola (e os professores) deve acomodar-se.

A perspetiva fortemente ancorada no mundo cívico surge particularmente evidenciada na docente de Economia e Contabilidade. Como expõe, o interesse da 
"sociedade" não reside apenas nos "conteúdos cognitivos". O mandato dos professores não existe como estando imune àquilo que são as demandas do contexto social em que a instituição escolar se insere; antes, ele deve acomodar-se às transformações e consequentes novas necessidades que emergem. Neste caso concreto, a inquirida foca-se naquilo que entende ser as novas expectativas das famílias, que delegam na escola a tarefa doméstica de "socialização", de inculcação de "novos valores". O mandato da escola - e, por inerência, dos professores - abrange este duplo propósito de educar e formar: "educar" enquanto "jovens" e "pessoas" e formar "cidadãos mais esclarecidos" - um trabalho de socialização política que não deixa de ser feito igualmente com os "conteúdos pré-estabelecidos" de carácter científico e que participa dessa mesmo trabalho qualificador (Resende, 2010). Neste arranjo composicional em que assenta o seu juízo, os mundos doméstico e cívico surgem em equivalência com o mundo industrial.

Outras perspetivas alinham-se neste entendimento a partir da questão do binómio saberes formais, de um lado, e educação e formação, do outro.

Considerando que a educação deve abarcar todos os domínios importantes para a formação integral dos alunos, não é aceitável eliminar ou secundarizar a educação sexual desse processo. Uma formação centrada apenas na transmissão de conteúdos e de saberes não faz sentido. É importante ter em atenção os valores, os princípios e as questões de natureza cívica, religiosa, cultural, política, sexual... (Questionário; A16; género masculino; professor de História; 23 anos de atividade; docente do Quadro)

A escola deve ter um papel preponderante na formação cívica e integral do aluno, pelo que não pode ser apenas um local de transmissão de conhecimentos científicos. É muito mais do que isso, pois tem um papel formativo. (Questionário; C16; género feminino; professora de Geografia; 29 anos de atividade; docente do Quadro)

Na hierarquia de grandezas em jogo, uma composição que consubstancie uma secundarização ou total invisibilização da educação sexual ("não é aceitável eliminar ou secundarizar") é perspetivada como inaceitável por parte da primeira inquirida. Um trabalho de socialização política exclusivamente assente no mundo industrial ("centrada apenas na transmissão de conteúdos e saberes") revela-se amputado, restrito face ao conjunto de questões de natureza doméstica e cívica - os "valores" e "princípios" e as diferentes preocupações de vasta amplitude (desde natureza "cívica" a "sexual") - que a escola deve integrar no seu cardápio de funções.

Igual perspetiva vislumbra-se na segunda inquirida. Uma conceção de escola circunscrita à "transmissão de conhecimentos científicos" é, no seu entender, uma 
visão cerceada com base na obrigação que assaca à instituição escolar: a de ter um "papel preponderante" na "formação cívica e integral do aluno".

Outros entendimentos, enquadrados na mesma categoria, colocam a tónica na crítica ao mundo industrial (no paradigma de eficácia escolar e consequente enfoque nos resultados escolares mensuráveis) enquanto princípio de justiça predominante no atual contexto do sistema de ensino. É o caso dos dois excertos que surgem em destaque.

A educação sexual é importante, mas descontextualizada do conjunto que avalia docentes, alunos e escolas coloca diversas dificuldades na escolha e tratamento de temáticas que são importantes para a formação do indivíduo.

O grau de exigência e a política de avaliação baseada em grelhas e com tradução numérica não contempla várias componentes de uma educação global. (Questionário; A2; género masculino; professor de Artes Visuais; 23 anos de atividade; docente do Quadro)

Trata-se igualmente de uma educação para a cidadania, de saúde pública e de gestão da felicidade do ser humano, pelo que é primordial ser integrada no espaço de reflexão que a escola deve proporcionar.

No entanto, sobrelevam os obstáculos colocados pelos decisores políticos, como a sobrecarga de programas curriculares, extensos, o vício dos exames (promoção do aluno passivo e que reproduz) (Questionário; B5; género masculino; professor de Educação Física; 11 anos de atividade; docente do Quadro)

Ambas as perspetivas incidem neste caso sobre os problemas concretos que os docentes enfrentam no contexto de uma escola sob o paradigma da eficácia. Todo o corpo de instrumentos de avaliação nas suas diferentes vertentes - a avaliação de cada professor, dos estabelecimentos de ensino e, por fim, dos conhecimentos adquiridos dos alunos - constituem objetos que enformam um modelo de ensino que, a partir dos mundos cívico e doméstico, coloca entraves à abordagem de temáticas "importantes para a formação do indivíduo". As "grelhas" com "tradução numérica", enquanto objetos de mensuração, deixam de fora o que entendem ser outras "componentes de uma educação global" que acabam por não ser contempladas na devida proporção na construção da oferta curricular.

No caso do professor de Educação Física, o seu entendimento da instituição escola revela-se basilar no juízo que constrói: a conceção da Escola como "espaço de reflexão" - por contraposição a uma circunscrição à transmissão de conhecimentos engrandecidos no mundo industrial e orientada por metas definidas. Este desiderato inspirado constitui igualmente o vetor para o cumprimento do mandato cívico e doméstico que atribui à instituição escolar: o desenvolvimento de uma “ 
educação para a cidadania", o acautelamento da "saúde pública" e a promoção da "felicidade do ser humano". A partir desta perspetiva, o olhar crítico da inquirida incide sobre as orientações políticas e as repercussões de um sistema educativo alicerçado no atual arranjo composicional no qual a grandeza industrial assume maior preponderância - traduzindo-se em "programas curriculares extensos", com enfoque nos instrumentos padronizados de aferição de competências e conteúdos científicos assimilados ("vício dos exames") e que em última análise projeta um paradigma de aluno que desqualifica a partir do mundo inspirado: o "aluno passivo" na relação de ensino-aprendizagem, que apenas "reproduz" o corpo de conhecimentos maquinalmente inculcados.

Outros inquiridos relevam igualmente a crítica ao mundo industrial na preponderância que assume. É o caso do último grupo de excertos apresentado.

"A escola deve ser um espaço de conhecimento por excelência e não estar centrada em estatística e resultados que pouco ou nada acrescentam na melhoria do sistema educativo." (Questionário; B20; género masculino; professor de Geografia; 14 anos de atividade; docente contratado)

'Os exames nacionais' mais uma vez julgo que estes são importantes. Mas a escola não deve girar à volta deles. A escola é mais um espaço de crescimento da pessoa do aluno o que deve contemplar uma dimensão cognitiva, mas também outras...! (Questionário; E6; género feminino; professora de Filosofia; 23 anos de atividade; docente do Quadro)

Ao serviço do entendimento da escola como "um espaço de conhecimento", num contexto de predomínio da ordem de grandeza industrial no funcionamento do sistema educativo - em que os elementos da "estatística" e dos "resultados" (mensuráveis) obtidos do ponto de vista da aprendizagem dos conteúdos passam a constituir o meio de prova privilegiado e engrandecido na avaliação do trabalho docente realizado nas escolas - , é o próprio conhecimento como bem visado que, no entender do primeiro inquirido, acaba pervertido. Subjacente está a alusão à redução substancialista (Thévenot, 2009) do trabalho docente, em que se o bem comum visado pelo conjunto de dispositivos industriais de governação escolar é a eficácia na transmissão do conhecimento, a norma padronizada acaba por se sobrepor a esse mesmo bem - neste caso, obstaculizando uma formação abrangente, e não circunscrita ao conhecimento na forma como é privilegiado no mundo industrial (mensurável por conjunto de instrumentos de aferição quantitativa).

Num enfoque convergente por parte da docente de Filosofia na composição de ordens de grandeza que constrói, os "'exames nacionais'" não surgem afastados 
na sua conceção em torno da estruturação e governação do trabalho da escola e dos professores. Contudo, como explicita, a gramática industrial não deve assumir-se como exclusiva ou hegemónica (o trabalho escolar "não deve girar à volta deles" [Exames Nacionais]). Esta preconização assenta num entendimento em que a dimensão dos "conteúdos cognitivos" deve estar articulada com "outras" dimensões (grandezas) - numa perspetiva tributária de uma conceção da escola enquanto "espaço de crescimento" do discente enquanto "pessoa" e não apenas como "aluno" recetor do trabalho dos conteúdos formais.

\section{Reflexões finais}

É sobretudo a partir dos anos 80 que se verifica uma revitalização das pesquisas científicas em torno da eficácia escolar (Normand, 2001). Esta corrente de pesquisa representa uma conceção da instituição escolar perspetivada por intermédio do prisma organizacional (numa qualificação industrial) - no sentido de entendimento daquela enquanto organização eficiente na produção de competências úteis e enquanto importante motor de desenvolvimento económico das sociedades - que concorre com uma conceção da escola enquanto programa institucional de socialização dos indivíduos (Dumay, 2011; Normand e Vincent-Dalud, 2012).

Este paradigma exerce, por sua vez, importantes implicações do ponto de vista das formas de governação escolar e de avaliação do trabalho docente, decorrentes dos seus pressupostos epistemológicos e ontológicos; inaugura um novo olhar sobre a forma como é pensada a governação dos estabelecimentos de ensino e a natureza do trabalho docente do ponto de vista das formas de regulação e avaliação (Dumay, 2011). Nomeadamente, emerge um controlo mais restrito e direto do trabalho docente em dois sentidos: na ótica dos resultados da sua ação educativa, mas também dos processos e práticas docentes (transmissão de modelos de comportamento e dispositivos pedagógicos) (Dumay, 2011).

Uma das características mais importantes deste paradigma reside na globalização das políticas escolares e na definição dos currículos - favorecendo justamente a sua perspetiva epistemológica e ontológica a legitimação de modos de regulação assentes na comparação de desempenhos através de instrumentos como o PISA e a construção de um espaço europeu de educação (Derouet e Normand, 2009; Thévenot, 2007). Esta abordagem planificadora e os instrumentos de gestão e vigilância (como padrões de práticas pedagógicas e organizacionais e ferramentas de prestações de contas) são marcas transversais, não obstante as diferenças e os processos de hibridização entre os diferentes países (Dumay, 2009). 
Ora, este novo modelo de regulação gestionária (Ogien, 2013) que se incrusta no funcionamento dos serviços do Estado, e neste caso particular da educação, é frequentemente analisado na ótica da sua influência na forma como os seus atores se percecionam enquanto profissionais de educação - como o mesmo age sobre a subjetividade dos professores (Dumay, 2011; Simons, 2007). Um importante papel na justificação, legitimação e implementação deste regime de governação reside na produção e circulação de informação relativamente ao trabalho desenvolvido nos diferentes sistemas educativos nacionais e estabelecimentos de ensino (seja ao nível das avaliações e comparações internacionais, seja no âmbito das políticas e dispositivos nacionais de avaliação) - e que consubstanciam uma forma de regulação e, acima de tudo, um regime de governação. Os diferentes instrumentos de produção de informação (e dispositivos de regulação), enquanto base para a aferição de desempenho, comportam uma forma de os professores conceberem e exercerem a sua atividade (Dumay, 2011; Simons, 2007).

Se os instrumentos criam um ambiento rico em informações (information-rich environment) que é tido como indispensável suporte da ação dos docentes para atingir níveis ótimos de desempenho (Simons, 2007), estes dispositivos são igualmente entendidos como mecanismos de poder: constituem um poder sinótico (ao invés de panótico) que autodisciplina os indivíduos (Simons, 2007). Este modo de governação, e os mecanismos de poder que institui, age sobre as representações dos agentes educativos, minimizando a sua reflexividade crítica em torno da educação (Dumay, 2011; Simons, 2007).

Contudo, um olhar a partir de uma sociologia dos envolvimentos dos atores, neste caso, dos professores, dá conta precisamente das operações de crítica e justificação, assentes no regime de justiça, que estes profissionais não deixam de desenvolver (Gouveia, 2017; Resende, 2010). Efetivamente, outras ordens de grandeza (que não a industrial) enquanto suporte de coordenação da ação revelam-se fortemente presentes nas conceções que os professores produzem em torno da sua atividade e das funções que atribuem à instituição escolar (Gouveia, 2017; Resende, 2010). No envolvimento com um ambiente equipado (Thévenot, 2002) enquanto suporte cognitivo da ação, e, neste caso em particular, um sistema educativo onde a gramática industrial adquire progressiva influência no seu funcionamento enquanto programa de justiça - em que um conjunto de dispositivos contribui para um ambiente que consubstancia uma governação por normas padronizadas (ambiente funcional e marcado pela circulação de informação sobre a eficácia do desempenho e respetivos instrumentos de aferição estandardizados) — , os professores não deixam de se afirmar criticamente em relação aos efeitos nocivos deste paradigma do ponto de vista dos efeitos no seu trabalho e do cumprimento daquilo que entendem ser o seu mandato enquanto profissionais de ensino (convocando em particular as gramáticas cívica, doméstica e 
inspirada como suporte dessas operações críticas, em composições diversas) ${ }^{5}$. Este modelo de governação entendido como incorporando um mecanismo de poder (Simons, 2007) não se traduz, neste sentido, num posicionamento e alinhamento acríticos por parte destes profissionais enquanto eles próprios agentes de normalização (Simons, 2007). É justamente a ausência de uma homologia entre políticas educativas e instrumentos de governação, de um lado, e os discursos e lógicas atuantes destes profissionais de ensino, do outro, que importa salientar.

Por outro lado, é necessário ter em conta que a sobreposição de regime de envolvimento em plano pode efetivamente conduzir à opressão de outros regimes de envolvimento. O regime de envolvimento por objetivos, enquanto marca da governação por normas padronizadas, pode exercer um efeito constrangedor sobre outros modos de coordenação (Thévenot, 2009, 2011, 2014). Ora, no quadro de uma instituição escolar à qual são atribuídas uma multiplicidade de funções e demandas, é justamente o problema da composição (e o reconhecimento social do mesmo) entre os diferentes regimes de envolvimento na ação que constitui um elemento central nas críticas que os professores constroem em torno do atual contexto profissional (Resende, 2010), sendo esta arte de composição entre diferentes imperativos e formas de regimes de envolvimento uma marca definidora das profissões intermediárias (como é o caso da docência) (Thévenot, 2014). Se os resultados quantificados estão no centro do escrutínio público e dos agentes políticos, outras demandas não deixam de recair sobre estes profissionais de ensino e que integram no seu mandato enquanto profissionais de ensino. É a ditadura do número (Resende, 2010) e o não reconhecimento das políticas públicas (e ferramentas de governação) deste trabalho de composição que adquire um lugar central nos juízos críticos destes profissionais.

Deste modo, pretende-se neste artigo evidenciar a importância de uma rutura com visões lineares da atividade docente segundo as quais "o ato de ensinar e a subjetividade do professor são ambos profundamente alterados pela nova gestão panótica" (Ball, 2001, p. xxxvi). O enfoque, através da Sociologia Pragmática, nas capacidades críticas dos atores fornece um importante roteiro analítico a explorar em torno funcionamento das organizações - e da instituição escolar em particular. No entanto, se o enfoque nesta pesquisa privilegia os discursos atuantes produzidos pelos professores captados nas entrevistas e no questionário aplicado, futuras incursões nas escolas com maior ênfase observação etnográfica permitirá uma maior profundidade na análise em torno dos envolvimentos múltiplos na atividade docente num contexto de performatividade escolar - um olhar mais minucioso das potencialidades e constrangimentos que decorrem da gramática industrial enquanto formato atuante incorporado nos diferentes dispositivos de governação e as tensões que se geram com as construções 
compósitas e plurais dos professores entre regimes de ação nos diversos momentos da sua conduta profissional quotidiana.

\section{Notas}

Por decisão pessoal, os autores do texto escrevem segundo o novo acordo ortográfico.

1 Os dados apresentados são recolhidos do projeto de doutoramento, financiado pela Fundação para a Ciência e Tecnologia, denominado "Porque se mobilizam os professores? Representações coletivas e coordenações de ações públicas dos professores do Ensino Básico e Secundário em função dos juízos plurais sobre o que é um bom profissional de ensino num contexto de incerteza" (SFRH/BD/80811/2011).

2 Por razões de economia de espaço, para mais informações sobre os procedimentos inerentes à construção dos cenários, cfr. L. Gouveia (2017).

3 Esta entrevista decorre num contexto de reforma educativa na estrutura curricular que importa ter em conta. No cumprimento do programa do XIX Governo Constitucional, e tendo Nuno Crato como Ministro da Educação, é efetuada em 2012 uma revisão nos currículos escolares, caracteriza-se por um reforço horário das disciplinas consideradas nucleares - Português e Matemática - e extinção das disciplinas de Formação Cívica, Estudo Acompanhado e Área de Projeto, criadas na governação do XVII Governo Constitucional.

4 Não sendo possível uma análise de todas as categorias de resposta construídas tendo em conta as restrições de espaço, privilegia-se neste texto a categoria que surge como claramente hegemónica. Por outro lado, importa considerar que muitas das outras categorias acabam por incidir sobre aspetos mais laterais relativamente àquilo que se pretende ser o objeto deste artigo, como é o caso da forma como a Educação Sexual deve ser administrada (se com uma disciplina autónoma, de forma transversal às diferentes disciplinas e/ou mediante projetos educativos). Não sendo de interesse despiciendo, a sua análise fica remetida para outro fórum.

5 Importa salientar que o regime de envolvimento em plano, estendido à eficácia industrial enquanto bem comum visado, não deixa de estar presente nos juízos produzidos por estes profissionais. O que surge acima de tudo criticado é a composição de ordens de grandeza e o que é percecionado como uma opressão da eficácia industrial na atual forma de governação do sistema educativo.

\section{Referências}

Abbot, A. (1988). The system of professions. An essay on the division of expert labor. Chicago: The University of Chicago Press.

Afonso, A. J. (1997). Para a configuração do Estado-providência na educação em Portugal, 1985-1995. Educação Sociedade Culturas, 7, 131-156. 
Afonso, A. J. (1998). Políticas educativas e avaliação educacional. Para uma análise sociológica da reforma educativa em Portugal (1985-1995). Braga: Universidade do Minho.

Ball, S. J. (2001). Global policies and vernacular politics in education. Currículo sem Fronteiras, 1(2), 27-43.

Barroso, J., e Carvalho, L. M. (2008). PISA: Un instrument de régulation pour relier des monde. Revue Française de Pédagogie, 1, 77-80.

Barroso, J., Carvalho, L. M., Fontoura, M., e Afonso, N. (2007). As políticas educativas como objecto de estudo e de formação em administração educacional. Sísifo. Revista de Ciências da Educação, 1, 5-20.

Boltanski, L., e Thévenot, L. (2006). On justification. Economies of worth. Princeton: Princeton University Press.

Breviglieri, M. (2007). L'arc expérientiel de l'adolescence: Esquive, combine, embrouille, carapace et étincelle. Éducation et Sociétés, 19, 99-113.

Danic, I., Delalande, J., e Rayou, P. (2006). Enquêtes auprès d'enfants et de jeunes. Objets, méthodes et terrains de recherche en sciences sociales, Rennes, PU Rennes.

Derouet, J.-L., e Derouet-Besson, M.-C. (2009). Crise du projet de la démocratisation de l'enseignement ou crise d'un modèle de démocratisation? Les recompositions parallèles des formes de l'État et des formes de justice. Em J.-L. Derouet, e M. C. Derouet-Besson (Eds.), Repenser la justice dans le domaine de l'éducation de la formation (pp. 3-23). Lyon: Peter Lang/ INRP.

Derouet, J.-L., e Normand, R. (2009). La mesure experte dans le gouvernement européen de la formation tout ao long da vie. Em F. Cantelli, M. R. i Escoda, J. Stavo-Debauge, e L. Pattaroni (Eds.), Sensibilités pragmatiques. Enquêter sur l'action publique (pp. 419-436). Peter Lang.

Dionísio, B. (2010). O paradigma da escola eficaz entre a crítica e a apropriação social. Sociologia, 20, 305-316.

Direção-Geral da Educação (DGE). (2019). Afetos e educação para a sexualidade. Disponível em http:/ / www.dge.mec.pt/afetos-e-educacao-para-sexualidade.

Dumay, X. (2009). Evaluation et accompagnement des établissements en Europe: Diversité et mécanismes d'hybridation. Les Cahiers de Recherche En Éducation et Formation, 76. Disponível em https://halshs.archives-ouvertes.fr/halshs-00561486

Dumay, X. (2011). La recherche sur l'efficacité de l'enseignement: transformations politiques et modèle d'évaluation. Évaluation et curriculum, 25, 57-68.

Foucault, M. (1991). Governmentality. Em G. Burchell, C. Gordon, e P. Miller (Eds.), The Foucault effect. Studies in governmentality (pp. 87-104). Chicago: The University of Chicago Press.

Foucault, M. (1998). O cuidado de si. História da sexualidade (Vol. III). Lisboa: Relógio d'Água.

Foucault, M. (2010). A hermenêutica do sujeito. São Paulo: Martins Fontes.

Gouveia, L. (2017). Porque se mobilizam os professores? Representações coletivas e coordenações de ações públicas dos professores do Ensino Básico e Secundário em função dos juízos plurais sobre o que é um bom profissional de ensino num contexto de incerteza (Tese de 
doutoramento). Universidade Nova de Lisboa, Faculdade de Ciências Sociais e Humanas, Lisboa.

Lima, L. C. (2011). Administração escolar. Porto: Porto Editora.

Lima, L. C. (2012). Aprender para ganhar, conhecer para competir: Sobre a subordinação da educação na sociedade da aprendizagem. São Paulo: Cortez Editora.

Lima, L. C. (2013). Organização escolar e democracia radical. Paulo Freire e a governação democrática da escola pública. São Paulo: Cortez Editora.

Lima, L. C., Estêvão, C. V., Silva, E., Torres, L., e Sá, V. (Eds.) (2006). Compreender a escola. Perspectivas de análise organizacional. Porto: Asa.

Normand, R. (2001). Gouverner la réussite scolaire. Une arithmétique politique des inégalités. Berna: Peter Lang.

Normand, R. (2005). La mesure de l'école: Politique des standards et management par la qualité. Cahiers de la recherche sur l'éducation et les savoirs, 1, 67-82.

Normand, R., e Vincent-Dalud, M. (2012). Sciences de gouvernement de l'éducation et réseaux transnationaux d'experts: La fabrication d'une politique européenne. Education et sociétés, 29, 103-123.

Ogien, A. (2013). Désacraliser le chiffre dans l'évaluation du secteur public. Versailles: Éditions Quae.

Resende, J. M. (2003). O engrandecimento de uma profissão. Os professores do ensino secundário público no Estado Novo. Coimbra: Fundação Calouste Gulbenkian.

Resende, J. M. (2010). A sociedade contra a escola? A socialização política escolar num contexto de incerteza. Lisboa: Instituto Piaget.

Resende, J. M. (2017). O Excel é que manda? As outras faces das desigualdades escolares. Em M. G. J. Setton, L. L. Torres, E. E. Gomes, T. Seabra, F. Jardim, B. Dionísio, e M. C. Corrochano (Orgs.), Mérito, desigualdades e diferenças: Cenários de injustiça escolar no Brasil e em Portugal (pp. 55-75). Alfenas: Brasil: Unifal-MG.

Resende, J. M., Beirante, D., e Gouveia, L. (2019, no prelo). A democracia ajuizada através das experiências escolares: Dilemas e desafios na sua persecução. Em III Colóquio Internacional de Ciências Sociais da Educação. Infância(s) e juventude(s) na educação contemporânea (A publicar brevemente).

Resende, J. M., e Gouveia, L. (2013). As artes de fazer o comum nos estabelecimentos de ensino: Outras aberturas sociológicas sobre os mundos escolares. Forum Sociológico, 23, 97-106.

Rui, S. (2013). ‘Où donc est le danger?': Participation et usages de Foucault. Participations, 6(2), 65-86.

Simons, M. (2007). 'To be informed': Understanding the role of feedback information for Flemish/European policy. Journal of Education Policy, 22(5), 531-548.

Thévenot, L. (1986). Les investissements de forme. Em L. Thévenot (Ed.), Conventions economiques (pp. 21-71). Paris: Presses Universitaires de France.

Thévenot, L. (1990). L'action que convient. Em P. Pharo, e L. Quéré (Eds.), Les formes de l'action (pp. 39-69). Paris: Ed. de l'EHESS.

Thévenot, L. (2002). Which road to follow? The moral complexity of an 'equipped' 
humanity. Em J. Law, e A. Mol (Eds.), Complexities. Social studies of knowledge practices (pp. 53-87). Durham e Londres: Duke University Press.

Thévenot, L. (2006). L'action au pluriel. Sociologie des régimes d'engagement. Paris: Éditions La Découvert.

Thévenot, L. (2007). La mise en place d'un gouvernement par les normes à l'échelle européenne. Em J.-L. Derouet, e R. Normand (Eds.), L'Europe de l'éducation: Entre management et politique (pp. 55-62). Lyon: Institut National de Recherche Pédagogique.

Thévenot, L. (2009). Governing life by standards. A view from engagements. Social Studies of Science, 39(5), 793-813.

Thévenot, L. (2011). Conventions for measuring and questioning policies: The case of 50 years of policy evaluations through a statistical survey. Historical Social Research, $36,192-217$.

Thévenot, L. (2014). Voicing concern and difference: From public spaces to commonplaces. European Journal of Cultural and Political Sociology, 1(1), 7-34.

Data de submissão: 23/04/2019 | Data de aceitação: 24/09/2019 